\title{
Hey Saussure...
}

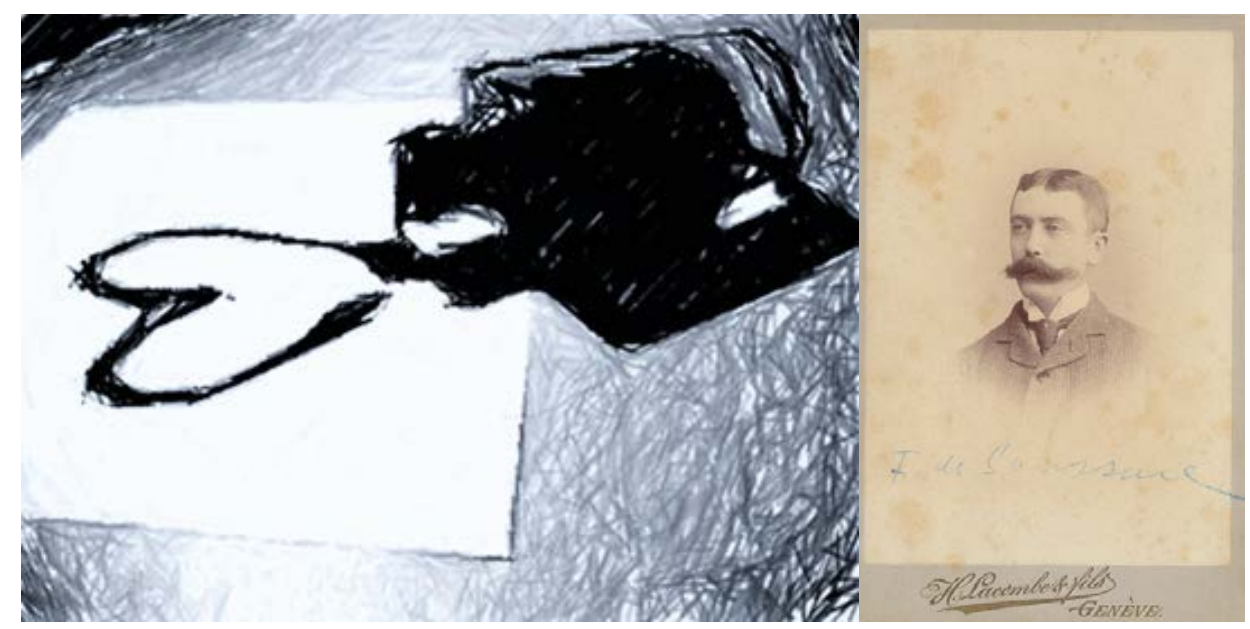

I lost my heart for a linguist

A man made of letters,

A man full of puzzles and loneliness

Yet, remarkably lovely and charming.

I lost my soul for a thinker

Whose miracle eyes

Penetrate into the deepest places of your heart

And still no judgements are settled.

Oh, unexplainable feelings, joy without boundaries,

Ideal balance between desire, hunger, tenderness,

Care and intimacy.

And now, I might find my whole life and thoughts

Lost to just one man, for just one name,

A name that fulfils me and make me complete,

And that is only you FdS...

\section{Eliette Karajan}

